\title{
BMJ Open Major health-related behaviours and mental well-being in the general population: the Health Survey for England
}

\author{
Saverio Stranges, ${ }^{1}$ Preshila Chandimali Samaraweera, ${ }^{1,2}$ Frances Taggart, ${ }^{1}$ \\ Ngianga-Bakwin Kandala, ${ }^{1}$ Sarah Stewart-Brown ${ }^{1}$
}

To cite: Stranges S, Samaraweera PC, Taggart F, et al. Major health-related behaviours and mental wellbeing in the general population: the Health Survey for England. BMJ Open 2014;4:e005878. doi:10.1136/bmjopen-2014005878

- Prepublication history and additional material is available. To view please visit the journal (http://dx.doi.org/ 10.1136/bmjopen-2014005878).

Received 9 June 2014 Revised 26 July 2014 Accepted 6 August 2014

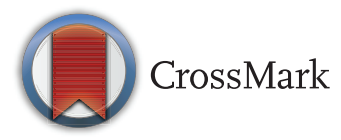

${ }^{1}$ Statistics and Epidemiology Unit, Division of Health Sciences, University of Warwick Medical School, Coventry, UK

${ }^{2}$ Ministry of Health, Sri Lanka

Correspondence to Dr Saverio Stranges; S.Stranges@warwick.ac.uk

\section{ABSTRACT}

Background: Major behavioural risk factors are known to adversely affect health outcomes and be strongly associated with mental illness. However, little is known about the association of these risk factors with mental well-being in the general population. We sought to examine behavioural correlates of high and low mental well-being in the Health Survey for England.

Methods: Participants were 13983 adults, aged 16 years and older ( $56 \%$ females), with valid responses for the combined 2010 and 2011 surveys. Mental well-being was assessed using the WarwickEdinburgh Mental Well-being Scale (WEMWBS). ORs of low and high mental well-being, compared to the middle-range category, were estimated for body mass index (BMI), smoking, drinking habits, and fruit and vegetable intake.

Results: ORs for low mental well-being were increased in obese individuals (up to $1.72,95 \% \mathrm{Cl}$ 1.26 to 2.36 in BMI $40+\mathrm{kg} / \mathrm{m}^{2}$ ). They increased in a linear fashion with increasing smoking (up to 1.98 , $95 \% \mathrm{Cl} 1.55$ to $2.53,>20$ cigarettes/day) and with decreasing fruit and vegetable intake (up to $1.53,95 \%$ $\mathrm{Cl} 1.24$ to $1.90,<1$ portion/day); whereas ORs were reduced for sensible alcohol intake $(0.78,95 \% \mathrm{Cl} 0.66$ to $0.91, \leq 4$ units/day in men, $\leq 3$ units/day in women). ORs for high mental well-being were not correlated with categories of BMI or alcohol intake. ORs were reduced among ex-smokers $(0.81,95 \% \mathrm{Cl} 0.71$ to 0.92 ), as well as with lower fruit and vegetable intake (up to $0.79,95 \% \mathrm{Cl} 0.68$ to $0.92,1$ to $<3$ portions/day). Conclusions: Along with smoking, fruit and vegetable consumption was the health-related behaviour most consistently associated with mental well-being in both sexes. Alcohol intake and obesity were associated with low, but not high mental well-being.

\section{INTRODUCTION}

Major behavioural risk factors such as obesity, smoking, excess alcohol consumption and poor dietary patterns account for large shares of the burden of morbidity and mortality, both nationally and globally. ${ }^{1-3} \mathrm{~A}$ considerable body of observational and experimental evidence

\section{Strengths and limitations of the study}

This is the first comprehensive analysis of behavioural correlates of mental well-being in a large, nationally representative sample from the general population.

- Along with smoking, the behavioural risk factor most consistently associated with both low and high mental well-being in both sexes was fruit and vegetable consumption.

- Cross-sectional nature of the study allowed us to examine the associations between mental wellbeing and multiple behaviours, but it cannot establish the causality and temporality of the observed relationships.

- Physical activity was not included in these analyses because data on this behaviour were not collected in the 2010 and 2011 Health Surveys for England.

also links these behaviours to the measures of health-related quality of life, mental illness and psychiatric comorbidities. ${ }^{4-7}$ There is evidence that up to $50 \%$ of tobacco is now smoked by people with a mental illness. ${ }^{8}$ Likewise, obesity, alcohol and drug misuse are frequently associated with mental disorders. ${ }^{9}{ }^{10}$ Mental health problems in childhood also predict the adoption of unhealthy lifestyles in adolescence. ${ }^{11}$

Positive mental health or mental well-being has recently emerged as an important predictor of overall health and longevity. ${ }^{12-14}$ Mental well-being is more than the absence of mental illness or psychiatric pathology. It implies 'feeling good' and 'functioning well' and includes aspects such as optimism, happiness, self-esteem, resilience, agency autonomy and good relationships with others. ${ }^{12-18}$ The case for the promotion of mental well-being has been advocated on both health and economic grounds, ${ }^{15}$ because mental illness is hugely costly to the 
individual and to society and lack of mental well-being underpins many physical diseases, unhealthy lifestyles and social inequalities in health. Recent compelling research suggests the economic benefits of promoting positive mental health are significant and widereaching. ${ }^{19}{ }^{20}$ As a consequence, mental well-being now assumes an important place in mental health and public health policy. ${ }^{16-18}$

Epidemiological evidence on the behavioural correlates of mental well-being is sparse. The Health Survey for England $^{21}$ collected data on mental well-being in 2010 and 2011 using the Warwick-Edinburgh Mental Well-being Scale (WEMWBS), ${ }^{22}$ as well as information on body weight, smoking, alcohol consumption, and fruit and vegetable lifestyle intake. We sought to quantify cross-sectional associations between these behavioural risk factors and mental well-being in this large representative sample of the English adult population.

\section{METHODS}

Study population

The Health Survey for England (HSE) is an annual survey of a nationally representative population sample of England. Detailed information is collected on mental and physical health, health-related behaviours, demographic and socioeconomic characteristics of people aged 16 years and over at private residential addresses. $^{21} 23$ Both 2010 and 2011 HSE included general population samples of adults, representative of the whole population at national and regional level. A total of 8420 adults were interviewed in the 2010 HSE, while a total of 8610 adults were interviewed in the 2011 HSE, with a $66 \%$ household response rate in both years. Of these 17030 adults, 3047 (17.9\%) had missing data on mental well-being scores. For this analysis, data for the 13983 adults who participated in the core surveys and with valid responses for the combined 2010 and 2011 data sets were used (see online supplementary table S1 for comparison between participants with and without a complete set of data).

\section{Mental well-being}

The Warwick-Edinburgh Mental Well-being Scale (WEMWBS) was administered in both 2010 and 2011. This scale is a well validated, popular measure currently used to monitor mental well-being in the English public health outcomes framework and the Scottish Government's Mental Health Indicators data set. ${ }^{22} 2425$ Valid responses, available for $13983(82.1 \%)$ of respondents for the combined 2010 and 2011 data sets, were used to define three population groups: more than one SD from the mean in either direction (top 15th centile: WEMWBS score 60-70; and bottom 15th centile: WEMWBS score 14-42) and the remainder (16th percentile to 84th percentile: WEMWBS score 43-59). In the first series of models, ORs were generated for the low mental well-being group compared to the middle-range group and in the second series for the high mental wellbeing group compared to the middle-range group.

\section{Health-related behavioural risk factors}

Body mass index (BMI), computed by dividing weight in kilograms by height in meters squared, was categorised according to WHO guidelines, ${ }^{26}$ underweight, BMI less than $18.5 \mathrm{~kg} / \mathrm{m}^{2}$; normal weight, BMI $18.5-24.9 \mathrm{~kg} / \mathrm{m}^{2}$ (reference category); overweight, BMI $25-29.9 \mathrm{~kg} / \mathrm{m}^{2}$; class I/II obesity, BMI $30-39.9 \mathrm{~kg} / \mathrm{m}^{2}$; class III or extreme obesity, BMI $40+\mathrm{kg} / \mathrm{m}^{2}$.

Alcohol consumption was categorised in accordance with national guidelines ${ }^{27}$ as: never-drinkers (reference category), sensible drinkers ( $\leq 4$ units/day/men or $\leq 3$ units/day/women), hazardous drinkers ( $>4$ and $\leq 8$ / men or $>3$ and $\leq 6 /$ women), harmful drinkers ( $>8$ units/day/men or $>6$ units/day women) or ex-drinkers.

Smoking habits were categorised as: never-smokers (reference category), light smokers $(<10 /$ day), moderate smokers $(10-<20 /$ day $)$, heavy smokers $(>20 /$ day $)$ or ex-smokers.

Fruit and vegetable intake was categorised on the basis of daily intake as: five or more portions (reference category), three to less than five portions, one to less than three portions or less than one portion based on current national and international guidelines. ${ }^{28} 29$

Data on physical activity were not collected in either the 2010 or 2011 surveys.

\section{Sociodemographic characteristics}

The following sociodemographic variables were included as covariates in regression models: age, categorised as: 16-34, 35-54, 55+; gender; ethnicity: white, Indian and Pakistani (including mixed race), Afro-Caribbean and African (including mix race), Chinese and other Asian, and other; employment status: employed, unemployed seeking work, retired, economically inactive; marital status: single, married/civil partnership/cohabitee, divorced/separated/widowed; educational attainment (NVQ4/NVQ5/degree or equivalent, higher education below degree, NVQ3/GCE A level equivalent, NVQ2/ GCE O level equivalent, NVQ1/CSE or other grade equivalent, no qualification) and equivalised household income in quintiles. In order to maximise sample size and avoid bias, missing values were included for all covariates.

\section{Statistical analysis}

For descriptive analyses of baseline characteristics (table 1), $\chi^{2}$ tests were used to determine the significance of any differences in the distributions of the health-related behavioural variables across categories of WEMWBS scores (low, middle, high). Unadjusted (model 1), partially adjusted (age and sex; model 2) and fully adjusted (age, sex, behavioural and sociodemographic correlates; model 3) logistic regression modelling was used to generate odds of low mental well-being compared with middle range (table 2), and high mental well-being 
Table 1 Baseline Characteristics of participants by category of WEMWBS groups in HSE 2010/2011 $(n=13983)^{*}$

\begin{tabular}{|c|c|c|c|c|}
\hline \multirow[b]{2}{*}{ Variable } & \multicolumn{3}{|c|}{ WEMWBS Score } & \multirow[b]{2}{*}{$p$ Value } \\
\hline & Low (14-42) & Middle (43-59) & High (60+) & \\
\hline N subjects (13983) & $2252(16.1)$ & $9446(67.6)$ & 2285 (16.3) & \\
\hline \multicolumn{5}{|l|}{ BMI } \\
\hline $18.5 \mathrm{~kg} / \mathrm{m}^{2}$ to $25 \mathrm{~kg} / \mathrm{m}^{2}$ & $617(27.4)$ & $2896(30.7)$ & $673(29.5)$ & $P<0.001$ \\
\hline$<18.5 \mathrm{~kg} / \mathrm{m}^{2}$ & $43(1.9)$ & $108(1.1)$ & $27(1.1)$ & \\
\hline $25 \mathrm{~kg} / \mathrm{m}^{2}$ to $<30 \mathrm{~kg} / \mathrm{m}^{2}$ & $624(27.7)$ & $3158(33.5)$ & $799(35.0)$ & \\
\hline $30 \mathrm{~kg} / \mathrm{m}^{2}$ to $<40 \mathrm{~kg} / \mathrm{m}^{2}$ & $508(22.6)$ & $1901(20.1)$ & $461(20.1)$ & \\
\hline $40+\mathrm{kg} / \mathrm{m}^{2}$ & $92(4.1)$ & $192(2.0)$ & $47(2.1)$ & \\
\hline Missing & 368 (16.3) & $1191(12.6)$ & $278(12.2)$ & \\
\hline \multicolumn{5}{|l|}{ Alcohol drinking } \\
\hline Never drinker & $828(36.8)$ & 2770 (29.3) & $712(31.2)$ & $p<0.001$ \\
\hline$\leq 4$ units/day/men or $\leq 3$ units/day/women & $498(22.1)$ & $2846(30.1)$ & $698(30.5)$ & \\
\hline$>4$ and $\leq 8 /$ men or $>3$ and $\leq 6 /$ women & $320(14.2)$ & $1642(17.4)$ & $407(17.8)$ & \\
\hline$>8$ units/day/men or $>6$ units/day women & $406(18.0)$ & $1738(18.4)$ & 347 (15.2) & \\
\hline Ex-Drinker & $188(8.3)$ & $406(4.3)$ & $110(4.8)$ & \\
\hline Missing & $12(0.5)$ & $44(0.5)$ & $11(0.5)$ & \\
\hline \multicolumn{5}{|l|}{ Smoking } \\
\hline Never Smoking & $874(38.8)$ & 4605 (48.8) & $1220(53.4)$ & $P<0.001$ \\
\hline Light Smoker <10/day & $197(8.7)$ & $621(6.6)$ & $127(5.6)$ & \\
\hline Moderate Smoker 10 to <20/day & $272(12.1)$ & $695(7.4)$ & $138(6.0)$ & \\
\hline Heavy Smoker >20/day & $207(9.1)$ & $338(3.6)$ & $57(2.5)$ & \\
\hline Ex-Smoker & $697(31.0)$ & $3160(33.5)$ & $736(32.2)$ & \\
\hline Missing & $8(0.3)$ & $24(0.1)$ & $7(0.3)$ & \\
\hline \multicolumn{5}{|l|}{ Fruit and vegetable intake } \\
\hline 5 or more portions/day & 457 (20.3) & $2556(27.1)$ & 765 (33.5) & $P<0.001$ \\
\hline 3 to $<5$ portions /day & $594(26.4)$ & 3046 (32.2) & $717(31.4)$ & \\
\hline 1 to $<3$ portions/day & $881(39.1)$ & 3057 (32.4) & $648(28.4)$ & \\
\hline$<1$ portion/day & $320(14.2)$ & 782 (08.3) & $155(6.8)$ & \\
\hline Missing & $0(0.0)$ & $5(0.1)$ & 0. (0.0) & \\
\hline \multicolumn{5}{|l|}{ Age (years) } \\
\hline $16-34$ & $553(24.6)$ & $2467(26.1)$ & $519(22.7)$ & $P<0.001$ \\
\hline $35-54$ & $904(40.1)$ & $3467(36.7)$ & 677 (29.6) & \\
\hline $55+$ & 795 (35.3) & 3512 (37.2) & $1089(47.7)$ & \\
\hline \multicolumn{5}{|l|}{ Gender } \\
\hline Male & $936(41.6)$ & 4185 (44.3) & $1024(44.8)$ & $P=0.041$ \\
\hline Female & $1316(58.4)$ & $5261(55.7)$ & 1261 (55.2) & \\
\hline \multicolumn{5}{|l|}{ Marital status } \\
\hline Single & $560(24.9)$ & $1711(18.1)$ & $360(15.8)$ & $P<0.001$ \\
\hline Married/Civil partnership/cohabitees & $1205(53.5)$ & $6320(66.9)$ & $1559(68.2)$ & \\
\hline Separated/Divorced/Widowed & $484(21.5)$ & $1415(15.0)$ & $365(16.0)$ & \\
\hline Missing & $3(0.1)$ & $0(0.0)$ & $1(0.0)$ & \\
\hline \multicolumn{5}{|l|}{ Education } \\
\hline NVQ4/NVQ5/Degree or equivalent & $327(14.5)$ & $2442(25.9)$ & $582(25.5)$ & $P<0.001$ \\
\hline Higher education below degree & $203(9.0)$ & 1095 (11.6) & $297(13.0)$ & \\
\hline NVQ3/GCE A Level equivalent & 335 (14.9) & $1526(16.2)$ & $343(15.0)$ & \\
\hline NVQ2/GCE O Level & $591(26.2)$ & $2143(22.7)$ & $446(19.5)$ & \\
\hline NVQ1/CSE other grade equivalent & $134(6.0)$ & $395(4.2)$ & $106(4.6)$ & \\
\hline Foreign/other & 27 (1.2) & $151(1.6)$ & $53(2.3)$ & \\
\hline No qualifications & $631(28.0)$ & $1681(17.8)$ & $456(20.0)$ & \\
\hline Missing & $4(0.2)$ & $13(0.1)$ & $2(0.1)$ & \\
\hline \multicolumn{5}{|l|}{ Equivalised household income } \\
\hline Lowest $(\leq £ 11676.65)$ & $519(23.0)$ & $1015(10.7)$ & $253(11.1)$ & $P<0.001$ \\
\hline Second lowest (>£11676.65-<19117.65) & $420(18.7)$ & $1476(15.6)$ & $332(14.5)$ & \\
\hline 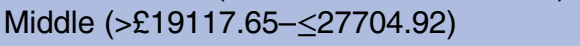 & $354(15.7)$ & $1619(17.1)$ & $373(16.3)$ & \\
\hline Second highest (>27704.92- $\leq 47794.12)$ & 276 (12.3) & $1863(19.7)$ & $428(18.7)$ & \\
\hline Highest $(>£ 47794.12)$ & $256(11.4)$ & 1857 (19.7) & $473(20.7)$ & \\
\hline Missing & $427(19.0)$ & $1616(17.1)$ & $426(18.6)$ & \\
\hline
\end{tabular}


Table 1 Continued

\begin{tabular}{|c|c|c|c|c|}
\hline \multirow[b]{2}{*}{ Variable } & \multicolumn{3}{|c|}{ WEMWBS Score } & \multirow[b]{2}{*}{$p$ Value } \\
\hline & Low (14-42) & Middle (43-59) & High (60+) & \\
\hline \multicolumn{5}{|l|}{ Employment status } \\
\hline In employment & $975(43.3)$ & $5621(59.5)$ & $1183(51.6)$ & $P<0.001$ \\
\hline Unemployed seeking work & $1439(6.3)$ & $445(4.7)$ & $108(4.7)$ & \\
\hline Retired & 525 (23.3) & $2182(23.1)$ & $721(31.6)$ & \\
\hline Other economically inactive & 605 (26.9) & $1181(12.5)$ & $271(11.9)$ & \\
\hline Missing & $4(0.2)$ & $17(0.2)$ & $2(0.1)$ & \\
\hline \multicolumn{5}{|l|}{ Ethnicity } \\
\hline White & 2064 ( (91.7) & 8419 (89.1) & $1951(85.4)$ & $P<0.001$ \\
\hline Indian and Pakistani & $61(2.7)$ & $242(2.6)$ & $91(4.0)$ & \\
\hline African Caribbean & $57(2.5)$ & $487(5.2)$ & $151(6.6)$ & \\
\hline Chinese and Other Asian mix & $44(2.0)$ & $195(2.1)$ & $58(2.5)$ & \\
\hline Other & $23(1.0)$ & $93(1.0)$ & $31(1.4)$ & \\
\hline Missing & $3(0.1)$ & $10(0.1)$ & $3(0.1)$ & \\
\hline
\end{tabular}

compared with middle range (table 3) for different levels of behavioural correlates using SPSS V.21. The selection of covariates and confounders for multivariate analyses was based on a previous study from the same data sets, which focused on demographic and socioeconomic correlates of mental well-being. ${ }^{30}$

To examine whether the association of each behavioural correlate of low and high mental well-being differed between men and women, we performed tests for interaction between sex and each of the selected correlates; sex-stratified results are displayed in supplementary tables for both low and high mental well-being (see supplementary tables S2 and S3, respectively).

\section{RESULTS}

Table 1 shows descriptive characteristics of study participants $(\mathrm{N}=13$ 983) by WEMWBS groups (low, middle and high). Significant associations were found in the distribution of the four major behaviours across the three categories of mental well-being. Specifically, individuals in the lowest mental well-being category (WEMWBS score 14-42) were more likely to be obese, current smokers, never-drinkers or ex-drinkers and to report lower intakes of fruit and vegetables than those in the middle or highest category. Individuals in the highest mental wellbeing category (WEMWBS score 60-70) were more likely to be never smokers and to report higher intakes of fruit and vegetables than those in the low or middle category; they were more likely to be overweight, but not more likely to be ideal body weight.

With regard to low mental well-being (table 2) as compared to the middle-range category, in fully adjusted models odds ratios were increased for obese individuals $\left(1.24,95 \%\right.$ CI 1.04 to 1.43 , BMI $30-40 \mathrm{~kg} / \mathrm{m}^{2} ; 1.72,95 \%$ CI 1.26 to 2.36 , BMI: $40+\mathrm{kg} / \mathrm{m}^{2}$ ); and reduced for sensible alcohol intake $(0.78,95 \%$ CI 0.66 to $0.91, \leq 4$ units/ day in men, $\leq 3$ units/day in women). They increased in a linear fashion with increasing smoking (up to 1.98, $95 \%$ CI 1.55 to $2.53,>20$ cigarettes/day) and decreasing fruit and vegetable intake (up to $1.53,95 \%$ CI 1.24 to $1.90,>1$ portion/day).

With regard to high mental well-being (table 3) as compared to the middle-range category, in fully adjusted models there were no significant associations across BMI or alcohol intake categories. Lower ORs of high mental well-being were found among ex-smokers (0.81, 95\% 0.71 to 0.92 ), as well as with reduced intakes of fruit and vegetables $(0.79,95 \%$ CI 0.68 to $0.92,1$ to $>3$ portions/ day; $0.83,95 \% \mathrm{Cl} 0.72$ to $0.96,3-5$ portions/day.

Findings were generally consistent with these overall results for female participants but less so for men. In sex-stratified analyses (see online supplementary table S2) increased ORs for low mental well-being were found in underweight or obese female participants, with no significant association across BMI categories among male participants. Likewise, increased ORs for low mental well-being were observed in both current and exsmokers among women, but not in male ex-smokers. Odds were increased in the lowest category of fruit and vegetable intake $(<1$ portion/day) in both sexes and reduced for sensible alcohol intake in both sexes. As to high mental well-being, in sex-stratified analyses (see online supplementary table S3) there were fewer significant associations. Specifically, ORs for high mental well-being were significantly reduced in ex-smokers of both sexes and in heavy female smokers, among harmful male drinkers, and across all categories of fruit and vegetable intake among female participants and one category in men.

\section{DISCUSSION}

This study examined the independent associations of a number of major health-related behaviours with mental well-being in the Health Survey for England, a large 
Table 2 Odds Ratios for low mental well-being (14-42), as compared to middle-range mental well-being (43-59), across lifestyle variables

\begin{tabular}{|c|c|c|c|c|c|c|}
\hline & $\begin{array}{l}\text { Model } 1 \text { Unadjusted } \\
\text { OR }(95 \% \mathrm{Cl})\end{array}$ & $\begin{array}{l}\text { Model } 2 \text { Partially } \\
\text { adjusted OR }(95 \% \mathrm{Cl})\end{array}$ & $\begin{array}{l}\text { Model } 3 \text { Fully } \\
\text { adjusted OR }(95 \% \mathrm{Cl})\end{array}$ & $\begin{array}{l}P \text { value for } \\
\text { significant ones }\end{array}$ & $\begin{array}{l}\text { P value for } \\
\text { linear trend }\end{array}$ & $\begin{array}{l}P \text { for interaction } \\
\text { with sex }\end{array}$ \\
\hline \multicolumn{7}{|l|}{ Body Mass Index $\left(\mathrm{kg} / \mathrm{m}^{2}\right)$} \\
\hline $18.5 \mathrm{~kg} / \mathrm{m}^{2}$ to $25 \mathrm{~kg} / \mathrm{m}^{2}$ & Ref & Ref & Ref & & & \\
\hline$<18.5 \mathrm{~kg} / \mathrm{m}^{2}$ & $1.87(1.30-2.69)$ & $1.82(1.26-2.61)$ & $1.46(0.95-2.24)$ & & 0.000 & 0.334 \\
\hline $25 \mathrm{~kg} / \mathrm{m}^{2}$ to $<30 \mathrm{~kg} / \mathrm{m}^{2}$ & $0.92(0.82-1.05)$ & $0.97(0.85-1.09)$ & $1.03(0.89-1.18)$ & & & \\
\hline $30 \mathrm{~kg} / \mathrm{m}^{2}$ to $<40 \mathrm{~kg} / \mathrm{m}^{2}$ & $1.25(1.10-1.43)$ & $1.31(1.14-1.50)$ & $1.24(1.04-1.43)$ & 0.012 & & \\
\hline $40+\mathrm{kg} / \mathrm{m}^{2}$ & $2.25(1.73-2.93)$ & $2.28(1.75-2.97)$ & $1.72(1.26-2.36)$ & 0.001 & & \\
\hline \multicolumn{7}{|l|}{ Alcohol drinking } \\
\hline Never drinker & Ref & Ref & Ref & & & 0.246 \\
\hline$\leq 4 /$ day/men or $\leq 3 /$ day/women & $0.59(0.52-0.66)$ & $0.59(0.52-0.67)$ & $0.78(0.66-0.91)$ & 0.002 & 0.777 & \\
\hline$>4$ and $\leq 8 /$ men or $>3$ and $\leq 6 /$ women & $0.65(0.57-0.75)$ & $0.66(0.57-0.76)$ & $0.82(0.69-0.99)$ & 0.043 & & \\
\hline$>8$ /day/men or $>6$ /day women & $0.78(0.68-0.89)$ & $0.79(0.69-0.91)$ & $0.87(0.73-1.04)$ & & & \\
\hline Ex-Drinker & $1.55(1.28-1.87)$ & $1.55(1.29-1.87)$ & $1.22(0.93-1.59)$ & & & \\
\hline \multicolumn{7}{|l|}{ Smoking } \\
\hline Never Smoking & Ref & Ref & Ref & & 0.000 & 0.866 \\
\hline Light Smoker <10/day & $1.67(1.40-1.99)$ & $1.70(1.43-2.03)$ & $1.45(1.15-1.80)$ & 0.001 & & \\
\hline Moderate Smoker 10 to $<20 /$ day & $2.06(1.76-2.41)$ & $2.08(1.78-2.44)$ & $1.56(1.27-1.92)$ & $<0.001$ & & \\
\hline Heavy Smoker $>20 /$ day & $3.16(2.62-3.81)$ & $3.21(2.67-3.87)$ & $1.98(1.55-2.53)$ & $<0.001$ & & \\
\hline Ex-Smoker & $1.16(1.04-1.30)$ & $1.16(1.04-1.30)$ & $1.15(0.99-1.32)$ & & & \\
\hline \multicolumn{7}{|l|}{ Fruit and vegetable intake } \\
\hline 5 or more portions/day & Ref & Ref & Ref & & 0.000 & 0.028 \\
\hline 3 to $<5$ portions /day & $1.09(0.96-1.25)$ & $1.09(0.96-1.25)$ & $0.97(0.82-1.14)$ & & & \\
\hline 1 to $<3$ portions/day & $1.61(1.42-1.83)$ & $1.64(1.44-1.86)$ & $1.11(0.94-1.31)$ & & & \\
\hline$<1$ portion/day & $1.29(1.94-2.70)$ & $2.35(1.99-2.78)$ & $1.53(1.24-1.90)$ & 0.000 & & \\
\hline
\end{tabular}


Table 3 Odds Ratios for high mental well-being (60+) as compared to middle-range mental well-being (43-59), across lifestyle variables

\begin{tabular}{|c|c|c|c|c|c|c|}
\hline & $\begin{array}{l}\text { Model } 1 \text { Unadjusted } \\
\text { OR }(95 \% \mathrm{Cl})\end{array}$ & $\begin{array}{l}\text { Model } 2 \text { Partially } \\
\text { adjusted OR }(95 \% \mathrm{CI})\end{array}$ & $\begin{array}{l}\text { Model } 3 \text { Fully adjusted } \\
\text { OR }(95 \% \mathrm{Cl})\end{array}$ & $\begin{array}{l}\text { P value for } \\
\text { significant ones }\end{array}$ & $\begin{array}{l}\text { P value for } \\
\text { linear trend }\end{array}$ & $\begin{array}{l}\text { P for interaction } \\
\text { with sex }\end{array}$ \\
\hline \multicolumn{7}{|l|}{ Body Mass Index $\left(\mathrm{kg} / \mathrm{m}^{2}\right)$} \\
\hline $18.5 \mathrm{~kg} / \mathrm{m}^{2}$ to $25 \mathrm{~kg} / \mathrm{m}^{2}$ & Ref & Ref & Ref & & 0.326 & 0.791 \\
\hline$<18.5 \mathrm{~kg} / \mathrm{m}^{2}$ & $1.08(0.70-1.65)$ & $1.18(0.76-1.81)$ & $0.92(0.54-1.55)$ & & & \\
\hline $25 \mathrm{~kg} / \mathrm{m}^{2}$ to $<30 \mathrm{~kg} / \mathrm{m}^{2}$ & $1.09(0.71-1.22)$ & $1.00(0.89-1.13)$ & $1.04(0.91-1.18)$ & & & \\
\hline $30 \mathrm{~kg} / \mathrm{m}^{2}$ to $<40 \mathrm{~kg} / \mathrm{m}^{2}$ & $1.04(0.92-1.19)$ & $0.94(0.82-1.07)$ & $1.00(0.86-1.17)$ & & & \\
\hline $40+\mathrm{kg} / \mathrm{m}^{2}$ & $1.05(0.75-1.46)$ & $0.99(0.71-1.38)$ & $1.01(0.70-1.46)$ & & & \\
\hline \multicolumn{7}{|l|}{ Alcohol Drinking } \\
\hline Never drinker & Ref & Ref & Ref & & 0.025 & 0.313 \\
\hline$\leq 4$ /day/men or $\leq 3 /$ day/women & $0.95(0.85-1.07)$ & $0.90(0.80-1.01)$ & $0.94(0.81-1.09)$ & & & \\
\hline$>4$ and $\leq 8 /$ men or $>3$ and $\leq 6 /$ women & $0.96(0.84-1.01)$ & $0.93(0.81-1.07)$ & $1.03(0.87-1.22)$ & & & \\
\hline$>8$ /day/men or >6 /day women & $0.78(0.67-0.90)$ & $0.80(0.69-0.93)$ & $0.93(0.77-1.11)$ & & & \\
\hline Ex-Drinker & $1.05(0.84-1.32)$ & $0.99(0.79-1.24)$ & $1.07(0.81-1.43)$ & & & \\
\hline \multicolumn{7}{|l|}{ Smoking } \\
\hline Never Smoking & Ref & Ref & Ref & & 0.003 & 0.641 \\
\hline Light Smoker <10/day & $0.77(0.63-0.94)$ & $0.83(0.68-1.02)$ & $0.84(0.65-1.07)$ & & & \\
\hline Moderate Smoker 10 to <20/day & $0.77(0.63-0.94)$ & $0.77(0.63-0.93)$ & $0.88(0.69-1.12)$ & & & \\
\hline Heavy Smoker >20/day & $0.62(0.46-0.83)$ & $0.51(0.46-0.81)$ & $0.72(0.51-1.02)$ & & & \\
\hline Ex-Smoker & $0.88(0.79-0.97)$ & $0.81(0.73-0.90)$ & $0.81(0.71-0.92)$ & 0.001 & & \\
\hline \multicolumn{7}{|l|}{ Fruit and Vegetable consumption } \\
\hline 5 or more portions/day & Ref & Ref & Ref & & 0.000 & 0.159 \\
\hline 3 to $<5$ portions /day & $0.79(0.70-0.88)$ & $0.79(0.71-0.89)$ & $0.83(0.72-0.96)$ & 0.010 & & \\
\hline 1 to $<3$ portions/day & $0.71(0.63-0.80)$ & $0.73(0.65-0.83)$ & $0.79(0.68-0.92)$ & 0.002 & & \\
\hline$<1$ portion/day & $0.66(0.55-0.80)$ & $0.71(0.58-0.85)$ & $0.86(0.68-1.09)$ & & & \\
\hline
\end{tabular}


nationally representative sample of the English adult population. ${ }^{21}{ }^{23}$ We used the WEMWBS as a measure of mental well-being. ${ }^{22}$ While this is the measure of choice in the UK for mental well-being, it is not a clinically validated measure of mental illness, but there is a high inverse correlation between WEMWBS scores and scores on the Center for Epidemiologic Studies Depression Scale (CES-D), a clinically valid measure of depression, widely used in population-based studies. ${ }^{31}$ A WEMWBS score of 42 , which defined the cut point for the low mental wellbeing group in this study, is below (clinically worse than) a CES-D score of 16 and just above (clinically better than) that consistent with a CES-D score of 26 , both cut points that have been used to define clinical populations of varying levels of severity. ${ }^{32}$ The bottom 15 th centile of the population in the current study thus comprised people whose mental health was poor to the point of probably warranting a clinical diagnosis of depression and is consistent with estimates of clinically relevant levels of mental illness in the UK population. ${ }^{33} 34$

Given this correlation, it is not surprising that our findings with regard to correlates of low mental wellbeing were in keeping with those relating to mental illness. ${ }^{8-10}$ They are, for example, in line with the unquestionable evidence on the comorbidity between alcohol use disorders and mental health problems such as depression or anxiety. ${ }^{35} \mathrm{~A}$ reduced risk of low mental well-being in people consuming alcohol within the sensible drinking limits is also in line with a U-shaped association, as supported by a large body of epidemiological data linking regular moderate consumption of alcohol to better health outcomes than abstinence or heavy drinking, across several populations worldwide. ${ }^{34}$

Our results are also generally consistent with observational studies of the association between BMI and measures of health-related quality of life, including both physical and mental health domains. ${ }^{35}$ We found that ORs of low mental well-being were increased among obese individuals, especially in those with class III or extreme obesity (BMI $40+\mathrm{kg} / \mathrm{m}^{2}$ ), whereas there was no increased risk of low mental well-being in the overweight. In a recent systematic review of observational studies, ${ }^{36}$ mental health, as assessed by the mental component score of the Short Form-36, was reduced among class III obese individuals, but was not significantly different among obese (class I and class II) participants, and increased among overweight adults, compared to normal weight individuals. In unadjusted and partially adjusted models, underweight (BMI $<18.5 \mathrm{~kg} / \mathrm{m}^{2}$ ) was also significantly associated with low mental well-being, thus suggesting a U-shaped association between body weight and mental health. On the other hand, the lack of associations between body weight and high mental well-being in our study could be driven by the use of BMI, a measure of relative weight rather than body fat distribution, which has been more strongly correlated with health. ${ }^{37}$
Our findings also mirror those from existing studies with regard to smoking, where evidence of correlation with both positive and negative measures of mental health have been presented, and there is some evidence that these associations may be causal. For example, a recent meta-analysis of observational studies examined changes in mental health after smoking cessation compared with continuing to smoke. ${ }^{38}$ The review pooled together results from 26 studies, which assessed anxiety, depression, mixed anxiety and depression, psychological quality of life, positive affect and stress. Findings showed that smoking cessation was associated with reduced depression, anxiety and stress, as well as with improved positive mood and quality of life compared with continuing to smoke. The effect size was as large for those with psychiatric disorders as for those without. In our study, reduced ORs of high mental well-being were found among ex-smokers, but this could be due to the correlational nature of the data, which does not take into account the effects of smoking cessation due to underlying illness. ${ }^{3}$

The novel finding in our study is that, along with smoking, the behavioural risk factor most consistently associated with mental health was fruit and vegetable consumption. The latter was associated with increased odds of high mental well-being and reduced odds of low mental well-being and these associations could be observed in men and women. This is not the first study to draw attention to a relationship between mental health, and fruit and vegetable consumption. ${ }^{39}$ For example, one recent study ${ }^{40}$ showed positive affect to be predictable on the basis of the current and previous days' fruit and vegetable consumption; likewise, nine different antioxidants found in fruit and vegetables have been shown in another study to be associated with optimism in middle-aged adults. ${ }^{41}$ We were only able to examine fruit and vegetable consumption up to five portions a day, but other studies have shown a doseresponse relationship between mental ${ }^{42}$ and physical health ${ }^{43}$ up to seven portions a day. Fruit and vegetable consumption might also be acting as a proxy for a complex set of highly correlated dietary exposures, including fish and whole grains, which might contribute to the observed associations. Our finding is, of course, in line with a large body of epidemiological and trial evidence on the beneficial role of fruit and vegetable intake in general well-being and prevention of major chronic disease across several populations and age groups. ${ }^{28-29}{ }^{44-46}$ Nevertheless, given the cross-sectional design of our study and the lack of definitive evidence on potential mechanisms linking fruit and vegetable intake with mental well-being, our findings need to be replicated in future longitudinal investigations to support the causality of the observed associations.

To the best of our knowledge, this is the first comprehensive analysis of health-related behavioural correlates of mental health in a nationally representative sample from the general population, which allowed for the possibility that associations with low and high mental well- 
being may not mirror each other. In studies in which mental health is examined as a continuum, positive findings such as those reported for alcohol intake may reflect strong associations with only one end of the continuum. Consistent associations across all levels of mental health are more suggestive of an underlying causal relationship.

Some limitations of the present study warrant discussion. First, we were not able to include physical activity in these analyses because data on this behaviour were not collected in the 2010 and 2011 Health Surveys for England. Fruit and vegetable intake is likely to represent an overall marker for healthy lifestyles including physical activity and it is important that other studies are undertaken to assess the extent to which our findings are independent of physical activity, a recognised determinant of mental health. ${ }^{47}$ Second, while the cross-sectional design of the study allowed us to examine the associations between mental well-being and multiple behaviours, it did not allow us to establish the causality and temporality of the observed relationships. Any putative effects of fruit and vegetable consumption on mental health could be short term ${ }^{40}$ and if this is the case, traditional approaches to establishing causality, in particular demonstrating a temporal relationship over prolonged periods, may be inappropriate. However, it remains that this study is not able to disentangle the chronological order or causal nature of the associations found, or to examine the effects of cumulative experience of lifestyle factors across the life course. Third, although our sample was nationally representative of the English adult population, it originated from a developed western country and finally the suboptimal participation rate $(66.0 \%)$ and the percentage of WEMWBS complete responders might reduce the generalisability of our findings to different populations and socioeconomic settings.

In closing, along with smoking, fruit and vegetable consumption was the health-related behaviour most consistently associated with low and high mental well-being in our study; these novel findings suggest that fruit and vegetable intake may play a potential role as a driver not just of physical but also of mental well-being in the general population. However, further studies should be carried out to investigate any potential for causality in this association.

Acknowledgements The Health Survey for England was commissioned by the Department of Health and was carried out by the Joint Health Survey Unit of National Centre for Social Research and department of Epidemiology and Public Health at University College London. The authors would like to thank all the participants in the Health Survey for England 2010 and 2011.

Contributors SS and SS-B developed the research hypothesis and wrote the final draft of the paper; SS and FT suggested the approach to analyses; PCS and N-BK performed the statistical analysis. All authors contributed to the study design, to the interpretation of the data and to the drafting of the paper.

Funding This research received no specific grant from any funding agency in the public, commercial or not-for-profit sectors.

Competing interests None.
Ethics approval The Health Survey for England was commissioned by the Department of Health and was carried out by the Joint Health Survey Unit of National Centre for Social Research and department of Epidemiology and Public Health at University College London.

Provenance and peer review Not commissioned; externally peer reviewed.

Data sharing statement No additional data are available.

Open Access This is an Open Access article distributed in accordance with the Creative Commons Attribution Non Commercial (CC BY-NC 4.0) license, which permits others to distribute, remix, adapt, build upon this work noncommercially, and license their derivative works on different terms, provided the original work is properly cited and the use is non-commercial. See: http:// creativecommons.org/licenses/by-nc/4.0/

\section{REFERENCES}

1. Lim SS, Vos T, Flaxman AD, et al. A comparative risk assessment of burden of disease and injury attributable to 67 risk factors and risk factor clusters in 21 regions, 1990-2010: a systematic analysis for the Global Burden of Disease Study 2010. Lancet 2012;380:2224-60.

2. Lozano R, Naghavi M, Foreman $\mathrm{K}$, et al. Global and regional mortality from 235 causes of death for 20 age groups in 1990 and 2010: a systematic analysis for the Global Burden of Disease Study 2010. Lancet 2012;380:2095-128.

3. Maheswaran $\mathrm{H}$, Petrou S, Rees $\mathrm{K}$, et al. Estimating EQ-5D utility values for major health behavioral risk factors in England $J$ Epidemiol Community Health 2013;67:172-80.

4. Stranges S, Notaro J, Freudenheim JL, et al. Alcohol drinking pattern and subjective health in a population-based study. Addiction 2006;101:1265-76.

5. Franco $\mathrm{OH}$, Wong $\mathrm{YL}$, Kandala N-B, et al. Cross-cultural comparison of correlates of quality of life and health status: the Whitehall II Study (UK) and the Western New York Health Study (US). Eur J Epidemiol 2012;27:255-65.

6. US Burden of Disease Collaborators. The state of US health, 1990-2010: burden of diseases, injuries, and risk factors. JAMA 2013;310:591-608.

7. Whiteford HA, Degenhardt L, Rehm J, et al. Global burden of disease attributable to mental and substance use disorders: findings from the Global Burden of Disease Study 2010. Lancet 2013;382:1575-86.

8. Lasser K, Boyd JW, Woolhander S, et al. Smoking and mental illness: a population-based prevalence study. JAMA 2000;284:2606-10.

9. White M, Adamson A, Chadwick T, et al. The changing social patterning of obesity: an analysis to inform practice and policy development. Public Health Research Consortium. Report No: 4, 2007.

10. Crawford V. Co-existing problems of mental disorder and substance misuse ('Dual Diagnosis'): a review of relevant literature. Royal College of Psychiatrists' Research and Training Unit. Final Report to the Department of Health, 2001.

11. Fergusson DM, Horwood LJ, Ridder EM. Show me the child at seven: the consequences of conduct problems in childhood for psychosocial functioning in adulthood. J Child Psychol Psychiatry 2005;46:837-49.

12. World Health Organization. Mental health: new understanding, new hope. The World Health Report. Geneva, Switzerland: World Health Organization, 2001.

13. Chida Y, Steptoe A. Positive psychological well-being and mortality: a quantitative review of prospective observational studies. Psychosom Med 2008:70:741-56.

14. Huppert FA. Psychological well-being: evidence regarding its causes and consequences. Appl Psychol Health Well-Being 2009;1:137-64

15. Jenkins $\mathrm{R}$, Meltzer $\mathrm{H}$, Jones PB, et al. Foresight Mental Capital and Wellbeing Project. Mental health: future challenges. London: The Government Office for Science, 2008. http://www.bis.gov.uk/assets/ BISCore/corporate/MigratedD/ec_group/116-08-FO_b.pdf

16. HM Government. Healthy Lives Healthy People: Our strategy for Public Health in England. 2010. https://www.gov.uk/government/ uploads/system/uploads/attachment_data/file/216096/dh_127424.pdf

17. HM Government. No health without mental health: a cross-governmental mental health outcomes strategy for people of all ages. 2011. https://www.gov.uk/government/uploads/system/ uploads/attachment_data/file/213761/dh_124058.pdf

18. HM Government. Preventing suicide in England: one year on. First annual report on the cross government strategy to save lives. January 2014.

19. Sainsbury Centre for Mental Health. The economic and social costs of mental illness. London: SCMH, 2003. 
20. Knapp M, McDaid D, Parsonage M, eds. Mental health promotion and mental illness prevention: the economic case. Personal Social Services Research Unit, London School of Economics and Political Science, 2011.

21. Mindell J, Biddulph JP, Hirani V, et al. Cohort profile: the Health Survey for England. Int J Epidemiol 2012;41:1585-93.

22. Tennant R, Hiller L, Fishwick R, et al. The Warwick-Edinburgh mental well-being scale (WEMWBS): development and UK validation. Health Qual Life Outcomes 2007;5:63.

23. Health Survey for England. Methodology and documentation. Data analysis and reporting. UK, 2011.

24. HM Government. Public health outcomes framework. http://www.dh. gov.uk/prod consum dh/groups/dh_digitalassets/@dh/@en/ documents/digitalasset/dh_132558.pdf, p 52

25. Scottish Government. Mental health indicators. http://www.healthscotland com/scotlandshealth/population/mental-health-indicators.aspx

26. WHO. World Health Organization (WHO) Expert Committee on Physical Status. The use and interpretation of anthropometry. Report of a World Health Organization Expert Committee. Geneva: WHO Technical Support, 1995, Series 854.

27. DoH. Safe. Sensible. Social. The Next Steps in the National Alcoho Strategy. 2007. http://www.dh.gov.uk/en/Publicationsandstatistics/ Publications/PublicationsPolicyAndGuidance/DH_075218 (accessed 1 Oct 2011)

28. DoH. 5 A DAY General Information. 2010. http://webarchive. nationalarchives.gov.uk/+/www.dh.gov.uk/en/Publichealth/ Healthimprovement/FiveADay/FiveADaygeneralinformation/DH_ 4002343 (accessed 1 Oct 2011).

29. Agriculture USDo, Services USDoHaH. U.S. Department of Agriculture and Dietary Guidelines for Americans. 7th edn. Washington, DC: US Government Printing Office, 2010. http://health.gov/dietaryguidelines/ dga2010/DietaryGuidelines2010.pdf (accessed 1 Oct 2011).

30. Stewart-Brown S, Samaraweera P, Taggart F, et al. Socio-economic gradients and mental health: implications for public health. $\mathrm{Br} J$ Psychiatry (in press)

31. Radloff LS. The CES-D Scale. Appl Psychol Meas 1977;1: 385-401.

32. Bianca D. Performance of the Warwick-Edinburgh Mental Well-Being Scale (WEMWBS) as a screening tool for depression in UK and Italy. http://www2.warwick.ac.uk/fac/med/research/platform/wemwbs/ development/papers/donatella_bianco-thesis.pdf

33. Singleton N, Bumpstead R, O'Brien M, et al. Psychiatric morbidity amongst adults living in private households in 2000. London: The Stationary Office, 2001.

34. McManus S, Brugha T, Meltzer $\mathrm{H}$, et al. Adult Psychiatric Morbidity in England 2007: results of a household survey. http://www.ic.nhs.uk/pubs/
35. Rehm J, Mathers C, Popova S, et al. Global burden of disease and injury and economic cost attributable to alcohol use and alcohol-use disorders. Lancet 2009;373:2223-33.

36. Ul-Haq Z, Mackay DF, Fenwick E, et al. Meta-analysis of the association between body mass index and health-related quality of life among adults, assessed by the SF-36. Obesity (Silver Spring) 2013;21:E322-7.

37. Bouchard C, Bray GA, Hubbard VS. Basic and clinical aspects of regional fat distribution. Am J Clin Nutr 1990;52:946-50.

38. Taylor G, McNeill A, Girling A, et al. Change in mental health after smoking cessation: systematic review and meta-analysis. BMJ 2014;348:g1151.

39. Rooney C, McKinley MC, Woodside JV. The potential role of fruit and vegetables in aspects of psychological well-being: a review of the literature and future directions. Proc Nutr Soc 2013:72:420-32.

40. White BA, Horwath CC, Conner TS. Many apples a day keep the blues away-daily experiences of negative and positive affect and food consumption in young adults. Br J Health Psychol 2013;18:782-98.

41. Blanchflower DG, Oswald AJ, Stewart-Brown S. Is psychological wellbeing linked to the consumption of fruit and vegetables? Soc Indic Res 2013;114:785-801.

42. Boehm JK, Williams DR, Rimm EB, et al. Association between optimism and serum antioxidants in the midlife in the United States study. Psychosom Med 2013;75:2-10.

43. Oyebode O, Gordon-Dseagu V, Walker A, et al. Fruit and vegetable consumption and all-cause, cancer and CVD mortality: analysis of Health Survey for England data. J Epidemiol Community Health 2014;68:856-62.

44. Myint PK, Welch AA, Bingham SA, et al. Fruit and vegetable consumption and self-reported functional health in men and women in the European Prospective Investigation into Cancer-Norfolk (EPIC-Norfolk): a population-based cross-sectional study. Public Health Nutr 2007;10:34-41.

45. Takaoka Y, Kawakami N. Fruit and vegetable consumption in adolescence and health in early adulthood: a longitudinal analysis of the statistics Canada's National Population Health Survey. BMC Public Health 2013;13:1206.

46. Hartley L, Igbinedion $\mathrm{E}$, Holmes J, et al. Increased consumption of fruit and vegetables for the primary prevention of cardiovascular diseases. Cochrane Database Syst Rev 2013;6: CD009874.

47. Penedo FJ, Dahn JR. Exercise and well-being: a review of mental and physical health benefits associated with physical activity. Curr Opin Psychiatry 2005;18:189-93. 